\title{
Pendant Dosing Unit
}

National Cancer Institute

\section{Source}

National Cancer Institute. Pendant Dosing Unit. NCI Thesaurus. Code C149749.

A unit of presentation used to represent the quantity of product that is found in a single discrete entity where the pharmaceutical dose form is a type of pendant. 